\title{
A workplace physical activity program at a public university in Mexico can reduce medical costs associated with type 2 diabetes and hypertension
}

\author{
Pablo Méndez-Hernández, D Sc, ${ }^{(1,2,3)}$ Darina Dosamantes-Carrasco, MSc, ${ }^{(1,4)}$ Carole Siani, D Sc, ${ }^{(1)}$ Yvonne N Flores, D Sc, ${ }^{(4,5)}$ \\ Armando Arredondo, D Sc, ${ }^{(6)}$ Irma Lumbreras-Delgado, MSc, ${ }^{(2)}$ Víctor M Granados-García, MSc, ${ }^{(7)}$ \\ Edgar Denova-Gutiérrez, MSc, ${ }^{(4,8)}$ Katia Gallegos-Carrillo, MSc, ${ }^{(4)}$ Jorge Salmerón, D Sc. ${ }^{(4,9)}$
}

\begin{abstract}
Méndez-Hernández P, Dosamantes-Carrasco D, Siani C, Flores YN, Arredondo A, Lumbreras-Delgado I, Granados-García VM, Denova-Gutiérrez E, Gallegos-Carrillo K, Salmerón J.

A workplace physical activity program at a public university in Mexico can reduce medical costs associated with type 2 diabetes and hypertension. Salud Publica Mex 20I I;54:20-27.
\end{abstract}

\begin{abstract}
Objective. To assess the impact of a workplace leisure physical activity program on healthcare expenditures for type 2 diabetes and hypertension treatment. Material and Methods. We assessed a workplace program's potential to reduce costs by multiplying the annual healthcare costs of patients with type 2 diabetes and hypertension by the population attributable risk fraction of non-recommended physical activity levels. Feasibility of a physical activity program was assessed among 425 employees of a public university in Mexico. Results. If 400 sedentary employees engaged in a physical activity program to decrease their risk of diabetes and hypertension, the potential annual healthcare cost reduction would be I 38880 US dollars. Each dollar invested in physical activity could reduce treatment costs of both diseases by 5.3 dollars. Conclusions. This research meets the call to use health economics methods to re-appraise health priorities, and devise strategies for optimal allocation of financial resources in the health sector.
\end{abstract}

Key words: physical activity; health care costs; health expenditures; type 2 diabetes mellitus; hypertension; Mexico
Méndez-Hernández P, Dosamantes-Carrasco D, Siani C, Flores YN, Arredondo A, Lumbreras-Delgado I, Granados-García VM, Denova-Gutiérrez E, Gallegos-Carrillo K, Salmerón J.

Un programa de actividad física en el lugar de trabajo en una universidad pública de México puede reducir los costos médicos asociados a la diabetes tipo 2 e hipertensión.

Salud Publica Mex 20I I;54:20-27.

\section{Resumen}

Objetivo. Evaluar el impacto de un programa de actividad física en el lugar de trabajo sobre la reducción de costos médicos directos relacionados con la diabetes tipo 2 y la hipertensión. Material y métodos. Calculamos el potencial de la actividad física para reducir costos médicos, multiplicando los gastos médicos anuales que realizan diabéticos e hipertensos, multiplicados por la fracción atribuible poblacional asociada a un nivel de actividad física insuficiente. La factibilidad de ejecutar el programa fue evaluada en $\mathbf{4 2 5}$ trabajadores de una universidad pública en México. Resultados. Si 400 trabajadores sedentarios participaran en un programa de actividad física recreativa para reducir su riesgo de diabetes e hipertensión, los costos médicos anuales reducirían en 138880 dólares. Cada dólar invertido en actividad física podría reducir 5.3 dólares en el tratamiento de ambas enfermedades. Conclusiones. Esta investigación evidencia la utilidad de los estudios costoeconómicos en salud para optimizar los recursos financieros en este sector.

Palabras clave: actividad física; costos del cuidado de la salud; gastos en salud; diabetes mellitus tipo 2; hipertensión; México

(I) Equipe MA2D - Laboratoire ERIC - Université Lyon I et Lyon 2. France.

(2) Facultad de Ciencias de la Salud, Universidad Autónoma de Tlaxcala. Tlaxcala, México.

(3) Departamento de Investigación, Secretaría de Salud de Tlaxcala. Tlaxcala, México.

(4) Unidad de Investigación Epidemiológica y en Servicios de Salud, Instituto Mexicano del Seguro Social, Delegación Morelos. Cuernavaca, México.

(5) UCLA Department of Health Services, School of Public Health and Jonsson Comprehensive Cancer Center. Los Angeles, EUA.

(6) Dirección de Innovación de Servicios y Sistemas de Salud, Instituto Nacional de Salud Pública (INSP). Cuernavaca, México.

(7) Unidad de Investigación Economía de la Salud, Instituto Mexicano del Seguro Social. México DF, México.

(8) Centro de Investigación en Ciencias Médicas, Universidad Autónoma del Estado de México. Toluca, México.

(9) Centro de Investigación en Salud Poblacional, INSP. Cuernavaca, México.

Received on: February 2I, 20II - Accepted on: September 8, 2011 Corresponding author: MSc Darina Dosamantes Carrasco. Calle 29, 820, Col. La Loma Xicoténcatl. 90062 Tlaxcala, Tlaxcala, México. E-mail: ddarina@hotmail.com 
P hysical inactivity is one of the main lifestyle factors associated with chronic disease, disability and death. ${ }^{1}$ Increasing sedentary forms of leisure, work and commuting are reducing Mexican population's energy expenditure, meaning that most Mexicans do not engage in enough physical activity to promote health. ${ }^{2}$ This situation brought about an increase in the prevalence of chronic health conditions such as metabolic syndrome, high blood pressure (HBP) and type 2 diabetes. ${ }^{3}$

Mexican population has high rates of overweight, obesity, large waist circumference and dyslipidemias. ${ }^{3,4}$ Cardiovascular disease is the leading cause of death for both sexes, and type 2 diabetes is the second cause of death among women and the third among men. ${ }^{5}$ Diabetes is a known risk factor for cardiovascular disease $\mathrm{e}^{3,6}$ and they often co-occur, exacting a toll of premature mortality, lost productivity, disability and loss of healthy life years. ${ }^{7}$ These diseases are also the main causes of healthcare utilization in Mexico, accounting for $9.5 \%$ of care for the uninsured and $13.5 \%$ among the insured. ${ }^{8}$

Encouraging regular physical activity (PA) is one of the Mexican government's main strategies for preventing chronic disease. Unfortunately, it has been ineffective due to lack of organization and inadequate exercise infrastructure and financing. ${ }^{9}$ For workers, the job site is an ideal setting for activities that promote the adoption and maintenance of healthy lifestyle behaviors. ${ }^{10}$ Helping employees to be more physically active has been shown to improve their physical and mental health, as well as their lifespan. PA may also generate economic benefits by reducing healthcare costs, lowering absenteeism, and increasing productivity. ${ }^{10,11}$

Despite the potential benefits of adequate levels of PA, in Mexico few studies have assessed the economic impact of workplace-based PA programs, leading to a lack of data that is needed to support economic arguments for encouraging workplace PA. ${ }^{11}$ This study investigates the potential for workplace PA programs to reduce the costs of certain chronic disease. Specifically, we assess the impact of a leisure workplace PA program in a university setting on the healthcare expenditures for type 2 diabetes and HBP treatment. This research also examines the feasibility of workplace PA programs in Mexico.

\section{Material and Methods}

\section{Study population}

We conducted a cross-sectional study of 425 employees of Universidad Autónoma de Tlaxcala (UAT) (Autonomous University of Tlaxcala), in Mexico from March to April 2008. Sample size was selected from a total of 2265 employees, using sample size calculations for cross-sectional studies, considering a 95\% confidence level. The sample was stratified by academic department, and the number of participants selected from each of 10 departments was proportional to its size. Random sampling was used to select the participants from each department. In this study, each subject signed an approved informed consent form, prior to entering the study. The ethic committee of the UAT approved the study protocol.

\section{Healthcare costs evaluation}

The study was conducted from the perspective of healthcare providers. We assumed that healthcare is provided by three main Mexican healthcare organizations: Instituto Mexicano del Seguro Social (Mexican Social Security Institute), Instituto de Seguridad y Servicios Sociales para los Trabajadores del Estado (State Employees Social Security and Services Institute), and Secretaría de Salud (Mexican Ministry of Health). We estimated treatment costs by measuring and valuing the costs of ambulatory and inpatient services. Existing information about resources for the treatment of patients was used based on a published study in Mexico. For this study, the authors assumed that resource utilization can be measured as the cost of managing an average patient based on the natural history of disease, the results of a shadow study, and the recommendations of expert clinicians and administrators. ${ }^{8}$

Inpatient care included initial and subsequent consultations, medical treatment, laboratory tests, chest x-rays, electrocardiography, hospitalizations and intensive care. Outpatient cases included initial and subsequent consultations with the general practitioner and specialists, laboratory tests and basic medications (table I). ${ }^{8}$ The unitary costs of these healthcare services were updated using the prices published in the "Diario Oficial de la Federación" (Official Journal of the Federation) of March 2008. ${ }^{12}$

\section{Healthcare costs reduction}

We estimated the potential impact of PA on healthcare cost reduction by multiplying the annual healthcare costs for patients with diabetes, HBP, or both, by the population risk fraction attributable to the non-recommended level of PA. ${ }^{13}$ Since other factors like age, body mass index (BMI) or family history might reduce the health benefit of recommended level PA, we adjusted our estimation by the percentage that PA failed to prevent diabetes and HBP. 
We used the following formula to estimate a PA program's impact on healthcare costs per sedentary employee at risk diabetes or HBP:

$H C R$ (for diabetes or HBP) $=[(H C)(P A R)]-[(H C)$ (PAR)](NPDR).

Where HCR is the estimated annual healthcare cost reduction per person engaging in the recommended amount of PA;

$\mathrm{HC}$ represents the estimated annual cost for the Mexican healthcare system of each diabetic patient (1 428 USD), or hypertensive patient (1 199 USD); 8,12

PAR is the population risk fraction of type 2 diabetes or HBP occurrence attributable to non-recommended amount of PA, $10.5 \%$ for diabetes and $12.9 \%$ for $\mathrm{HBP} ;{ }^{14}$ and

NPDR represents the non-prevented disease risk percentage: even people performing recommended levels of PA may suffer diabetes or HBP at rates of $7.5 \%$ and $12.5 \%$, respectively. ${ }^{15}$

We estimated the HCR for diabetes and HBP separately by assuming that medical costs differ due to chronic disease status. For instance, an average patient with diabetes and HBP costs $^{16}$ between 40 to $53 \%$ more (mean $46.5 \%$ ) than a diabetic patient without HBP or 30 to $150 \%$ more (mean $90 \%$ ) than a hypertensive patient without diabetes. ${ }^{17}$ Thus, we assumed chronic disease status reported in the adult participants of the Health Worker Cohort Study, where $46 \%$ had both conditions, i.e. were diagnosed with type 2 diabetes and HBP, while $18 \%$ were first diagnosed with HBP and then type 2 diabetes. ${ }^{14}$ To estimate the HCR for both diseases we added the $H C$ of: 1) the multiplication of the annual HC on each diabetic patient (1 428.3 USD) by 0.54 (percentage of diabetics only); 2) the multiplication of the annual HC on each diabetic patient, inflated at $46.5 \%$ (2 092.4 USD) by 0.46 (percentage of diabetics with $\mathrm{HBP})$; 3) the multiplication of the annual $\mathrm{HC}$ on each hypertensive patient (1 199.7 USD) by 0.82 (percentage of hypertensive patients only); and 4) the multiplication of the annual $H C$ on each hypertensive patient, inflated at $90 \%$ (2 279.4 USD) by 0.18 (percentage of hypertensive patients with diabetes).

\section{Cost-benefit rate}

We assessed the cost-benefit rate of the potential annual costs of a PA program (equipment, instructor salaries, laboratory tests for basic medical evaluation, organizational technology, and prizes for sports contests) versus medical cost reduction for type 2 diabetes and HBP (appendix).

\section{Sensitivity analysis}

One-way sensitivity analyses were conducted taking into account the variations of several key parameters: PAR, HC of type 2 diabetes, HBP, and both diseases; as well as the PA program costs and the sensitivity of the cost-benefit rate. Thus, we considered a variation of $20 \%$ for the PAR, and a discount rate of $5 \%$ for $H C .{ }^{18}$ Then, we estimated lower, intermediate, and higher PA program budgets. We also estimated the most sensitive worst-case scenario (higher PA program budget and lower HCR), the intermediate-case scenario (intermediate costs of PA program and estimated $H C R$ ), and the best-case scenario (lower PA program budget and upper HCR).

\section{Feasibility of a workplace physical activity program}

In order to evaluate the feasibility of a hypothetical workplace PA program for 400 participants $(\approx 25 \%$ of the sedentary employees at increased risk of diabetes and HBP), we considered the following: a) sports infrastructure and instructor availability; b) employees' stated preferences, by asking participants how much money they would be willing to pay to access three proposed hypothetical PA programs to engage in regular workplace PA: doing workplace PA, PA outside the workplace, or to use the public infrastructure for PA; c) employees' opinions about the circumstances they consider favorable to regular workplace PA; d) employees' motivation to practice PA on a regular basis; and e) employees' interest in specific types of PA. As well, we estimated hours of each recreational PA needed to achieve individual energy expenditure close to 1200 Kcal per week.

\section{Results}

The study population consisted of mainly middle-aged participants (mean age 34 years, $\mathrm{SD} \pm 11.5$ ). More than two-thirds were women, 239 participants $(56.3 \%)$ had a bachelor's degree or higher, 124 (29.2\%) were administrative employees, and their mean monthly household income was 221 USD.

Table I shows that the Mexican healthcare system spends an average of 1428.3 USD annually on each patient with diabetes and 1 199.7 USD annually on each hypertensive patient.

Table II reports that the medical cost reduction that would potentially result from engaging sedentary university employees in the recommended level of PA to reduce their risk of diabetes was estimated to be 138.7, and 136.2 USD to reduce their risk of diabetes 
Table I

\section{Mexican healthcare system aVerage annual expenditure on a tYPe 2 diabetes and hypertension patient}

\begin{tabular}{|c|c|c|c|c|c|c|}
\hline \multirow[t]{2}{*}{ Service } & \multicolumn{3}{|c|}{ Expenditure on a type 2 diabetes patient } & \multicolumn{3}{|c|}{ Expenditure on a hypertension patient } \\
\hline & Unit cost & Occurrences per year & Cost/year & Unit cost & Occurrences per year & Costs/year \\
\hline Consultation (General physician) & $\$ 35.7$ & I per month, I 2 per year & $\$ 428.4$ & $\$ 35.7$ & I per month, I 2 per year & $\$ 428.4$ \\
\hline Consultation (Specialist physician) & $\$ 56.8$ & 2 per year & $\$ 113.6$ & $\$ 56.8$ & 2 per year & $\$ 113.6$ \\
\hline Basic medication per month: insulin and hypoglycemic & $\$ 23.4$ & 12 per year & $\$ 280.8$ & $\$ 7.8$ & 12 per year & $\$ 93.6$ \\
\hline Laboratory tests of ambulatory cases* & $\$ 5.6$ & 6 per year & $\$ 33.6$ & $\$ 9.7$ & 6 per year & $\$ 58.2$ \\
\hline Chest x-ray & $\$ 18.6$ & I per year & $\$ 18.6$ & $\$ 18.6$ & I per year & $\$ 18.6$ \\
\hline Hospitalization ${ }^{\ddagger}$ & $\$ 329.9$ & $(\$ 329.90)(5$ days $)=\$ 1649.5$ & & $\$ 329.9$ & $(\$ 329.9)(3$ days $)=\$ 989.7$ & \\
\hline (medical treatment and laboratory tests & & $\S \$ 1649.5(0.10)=\$ 164.9$ & $\$ 164.9$ & & $\S \$ 989.7(0.10)=\$ 98.9$ & $\$ 98.9$ \\
\hline Intensive care $\mathrm{e}^{\ddagger}$ & $\$ 1,942.2$ & $(\$ 1942.2)(2$ days $)=\$ 3884.4$ & & $\$ 1,942.2$ & $(\$ 1942.2)(2$ days $)=\$ 3884.4$ & \\
\hline (medical treatment and laboratory tests) & & $\S \$ 3884.4(0.10)=\$ 388.4$ & $\$ 388.4$ & & $\$ \$ 3884.4(0.10)=\$ 388.4$ & $\$ 388.4$ \\
\hline Total & & & $\$ 1428.3$ & & & $\$ 1199.7$ \\
\hline
\end{tabular}

Costs were calculated in US dollars. Exchange rate: I dollar $=13.57$ Mexican pesos (July 10, 2009)

* Laboratory tests of ambulatory cases. For a type 2 diabetes patient: blood glucose, urine test, haematic biometry, urea and creatinine. For a hypertension patient: blood glucose, urea and creatinine, urine test and electrocardiography ${ }^{12}$

‡ Cost of hospitalization and intensive care per day: \$329.9 and \$1942.2 USD, respectively

a) For a type 2 diabetes patient, the average length of a hospital stay is 5 days per year, and the average length of an intensive care stay is 2 days per year ${ }^{8}$

b) For a hypertension patient, the average length of a hospital stay is 3 days per year, and the average length of an intensive care stay is 2 days per year ${ }^{8}$

$\S$ Risk of hospitalization and intensive care stay per year: On average, $10 \%$ of diabetic and hypertensive patients need hospitalizations and intensive care. Thus, we multiplied the average cost of the hospitalization and the intensive care stay by the factor $0.10^{8}$

Table II

\section{SENSITIVE ANALYSES FOR THE WORST- AND BEST-CASE SCENARIOS FOR REDUCING TYPE 2 DIABETES} AND HIGH BLOOD PRESSURE (HBP) ANNUAL HEALTHCARE COSTS

\begin{tabular}{|c|c|c|c|c|c|}
\hline $\begin{array}{l}\text { Population } \\
\text { attributable risk } \\
\text { (PAR) }\end{array}$ & $\begin{array}{l}\text { Healthcare } \\
\text { costs }(\mathrm{HC}) \\
\text { (per person) }\end{array}$ & $\begin{array}{c}\text { Healthcare } \\
\text { costs reduction } \\
(H C R) \text { (per person) }\end{array}$ & $\begin{array}{c}\text { Healthcare } \\
\text { costs reduction } \\
(H C R)(\text { per } 400 \text { persons })\end{array}$ & $\begin{array}{l}\text { Costs of PA program } \\
\text { at the workplace } \\
\text { (per } 400 \text { persons) }\end{array}$ & $\begin{array}{c}\text { Cost-benefit } \\
\text { rate } \\
\text { (Sensitive scenarios) }\end{array}$ \\
\hline \multicolumn{6}{|l|}{ Diabetes } \\
\hline $8.4(-20 \%)$ & $\$ 1356.9(-5 \%)$ & $\$ 102.0(-5 \%)$ & $\$ 40800$ (lower) & $\$ 16177$ (lower) & 0.80 (worst) \\
\hline 10.5 & $\$ 1428.3$ & $\$ 138.7$ & $\$ 55480$ (intermediate) & $\$ 25852$ (intermediate) & 0.46 (intermediate) \\
\hline $12.6(+20 \%)$ & $\$ 1499.7(+5 \%)$ & $\$ 169.1(+5 \%)$ & $\$ 67640$ (upper) & $\$ 32772$ (higher) & 0.24 (best) \\
\hline \multicolumn{6}{|l|}{ HBP } \\
\hline $10.3(-20 \%)$ & $\$ 1139.5(-5 \%)$ & $\$ 128.8(-5 \%)$ & $\$ 51520$ (lower) & $\$ 16177$ (lower) & 0.64 (worst) \\
\hline 12.9 & $\$ 1199.7$ & $\$ 136.2$ & $\$ 54480$ (intermediate) & $\$ 25852$ (intermediate) & 0.47 (intermediate) \\
\hline $15.5(+20 \%)$ & $\$ 1259.6(+5 \%)$ & $\$ 142.2(+5 \%)$ & $\$ 56880$ (upper) & $\$ 32772$ (higher) & 0.28 (best) \\
\hline \multicolumn{6}{|l|}{ Diabetes \& HBP } \\
\hline $8.9(-20 \%)$ & $\$ 2971.4(-5 \%)$ & $\$ 329.8(-5 \%)$ & $\$ 131920$ (lower) & $\$ 16177$ (lower) & 0.25 (worst) \\
\hline 11.1 & $\$ 3 \quad 127.8$ & $\$ 347.2$ & $\$ 138880$ (intermediate) & $\$ 25852$ (intermediate) & 0.19 (intermediate) \\
\hline $13.3(+20 \%)$ & $\$ 3284.2(+5 \%)$ & $\$ 364.6(+5 \%)$ & $\$ 145840$ (upper) & $\$ 32772$ (higher) & 0.11 (best) \\
\hline
\end{tabular}

HC, HCR and costs of PA program were calculated in US dollars. Exchange rate: I dollar = I3.57 Mexican pesos (July I0, 2009)

Costs of PA program at the workplace were estimated in considering the lower, intermediate, and upper costs for PA program promotion, equipment, instructor salaries, laboratory tests for basic medical evaluation, organizational technology, and prizes for sports contests

Worst-case scenario: lower PAR, HC, and HCR, but higher costs of PA program

Intermediate-case scenario: estimated PAR, HC, HCR, and intermediate costs of PA program

Best-case scenario: upper PAR, HC, and HCR, but lower costs of PA program 
and HBP, respectively. In the hypothetical case of 400 employees engaged in the leisure PA program recommended to decrease their risk of diabetes or hypertension, the potential annual reduction in health care costs would be 55480 USD for diabetes and 54480 USD for hypertension. The combined annual cost reduction for both diseases would be 138880 USD.

The results of the sensitivity analyses are also reported in table II. The sensitivity of the cost-benefit rate for the most sensitive worst-case scenario was 0.80 for diabetes, and 0.64 for HBP. For the best-case scenario, the cost-benefit rate was 0.24 for diabetes and 0.28 for HBP. In the intermediate-case scenario, the cost-benefit rate was 0.46 for diabetes and 0.47 for HBP. For the $H C R$ sensitive scenarios for both diabetes and HBP, the cost-benefit rate of the worst-case scenario was 0.25 ; the best-case scenario cost-benefit rate was 0.11 ; and the cost-benefit rate of the intermediate scenario was 0.19 .

A workplace PA program at the UAT seems highly feasible because it has the following sports facilities: 1 olympic-size swimming pool, 16 volleyball and basketball courts, 4 tennis courts, 3 fronton courts, 4 football/ soccer fields, 5 indoor football fields, and 2 gyms. The UAT also employs athletic instructors able to assist with many different sports.

Table III indicates the percentage of preference for each PA, as well as the estimated hours of each recreational PA needed to achieve individual energy expenditure close to $1200 \mathrm{Kcal}$ per week. To engage 400 university employees in workplace PA, we propose a program that takes into account the percentage of employees that reported an interest in each specific activity. For instance, since $12 \%$ of participants reported an interest in swimming, we consider that approximately 50 of the 400 potential participants would participate in this activity. To achieve an energy expenditure of 1200 Kcal per week, each of these participants must swim at least two hours per week in two sessions. To accommodate this schedule, we would propose having four swimming groups with approximately 30 individuals in each group.

Regarding university employees' stated PA program preferences, $34.3 \%$ showed interest in doing workplace PA, $28.5 \%$ were interested in doing PA outside the workplace and $25.4 \%$ were interested in active commuting. The employees saw the following as favorable conditions for regularly practicing PA: sports facilities (20\%), sports infrastructure near home or work (19\%), doing PA with friends, colleagues or family $(17 \%)$ and time availability (14\%). The employees' most important motivations for practicing regular PA were: to improve physical fitness (47\%), to be healthy (36\%), and to maintain weight (17\%) (data not shown).

\section{Discussion}

Our results indicate that engaging university employees in a PA program could help reduce the annual cost of

Table III

Estimated Weekly METs and Kilocalorie eXPenditure, according to the MET VAlUe of each PHySiCAL ACtivity

Physical Activity

I. Swimming (general)

2. Aerobics (general)

3. Yoga/Tai-chi

4. Basketball (match)

5. Spinning (general)

6. Running (general)

7. Dance (room)

8. Football soccer (match)

9. Indoor football (match)

10. Martial arts (general)

II. Volleyball (match)

12. Cycling (general)

13. Tennis (general)

I5. Skating (general)

Percentage
of preference

Estimated

MET value of each PA
Estimated hours to

spend $\approx 1200$ kcal per week

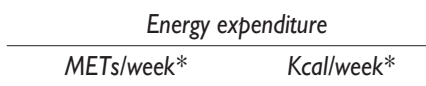

* Energy expenditure calculation of $1200 \mathrm{Kcal}$ per week for the activities was made in considering the mean weight of participants from the HWCS $(65 \mathrm{~kg})^{14}$ 
treating diabetes and HBP by preventing the development of these chronic diseases. ${ }^{11}$ Our findings suggest that by decreasing the risk of diabetes, PA programs could reduce the cost the Mexican healthcare system by 138 USD per person, which represents $9.7 \%$ of the medical costs related to this disease. PA programs could also result in savings of 136 USD per person by decreasing their risk of HBP, representing $11.3 \%$ of the medical costs.

Our estimates indicate that if 400 employees engaged in a PA program, healthcare costs might be reduced by 55000 USD per year for diabetes and 54000 USD per year for hypertension. Costs related to diabetes and HBP prevention might also be reduced by 138000 USD annually. This estimated potential reduction represents approximately $0.10 \%$ out of the total direct costs for type 2 diabetes projected in 2005. ${ }^{19}$

Although this study did not consider users' outof-pocket payments, PA could also reduce patients' personal medical expenditures for diabetes and hypertension, which include lab tests, monitoring, group therapy, education, etc. ${ }^{8}$ This savings are important since in middle-income countries like Mexico, 5-6 of every 10 dollars spent on diabetes and hypertension come from patients, ${ }^{21}$ meaning that these costs have an even greater impact on the uninsured. ${ }^{8}$

The results of this study show the economic advantage of implementing workplace PA programs and demonstrate the feasibility of implementing such programs in certain populations such as university employees. We also identified participants' opinions, motivations and preferences about recreational PA. These findings will help us develop strategies for implementing more effective PA programs in Mexico. Studies on the effectiveness of workplace PA promotion and intervention show that these programs can significantly mitigate some chronic illness risk factors (e.g. cholesterol levels, body composition), improve work-related outcomes (e.g. reduce absenteeism), and increase cardio-respiratory fitness and energy expenditure. .,22 $^{2}$

The results of the intermediate-case cost-benefit scenario indicates that each dollar invested in a recreational PA program might translate into a healthcare cost reduction of 2.2 USD for type 2 diabetes, 2.1 USD for HBP and 5.3 USD for both. A review of experimental, quasi-experimental and cross-sectional studies showed that an investment of one dollar in workplace PA programs might translate into a healthcare cost reduction of 3.4 USD. ${ }^{22} \mathrm{~A}$ meta-analysis of studies published from 1982 to 2005 shows that workplace PA programs may reduce pain-related absenteeism an average of $27 \%$, reduce healthcare costs by $26 \%$, and reduce disabilityrelated costs by 32 percen. ${ }^{23}$
Here, we show that workplace PA programs can be feasible and affordable; we also stress that they would be more so if planners consider the following points:

1. Workplace PA strategies must account for each employee's level of activity, in order to meet their specific needs. For instance, for those who have already a high level of workplace PA, lighter leisure activities such as hiking and yoga should be proposed.

2. We focused our analysis on university employees, since their workplace has the sports infrastructure, instructors, and budget needed to support PA. ${ }^{20}$ In the case of private enterprises without a sports infrastructure, it may be more appropriate to use public athletic infrastructure, such as that located at public schools and the municipality, or to subsidize use of private sports installations.

3. Although two thirds of the university employees report a willingness to exercise in order to decrease their risk of chronic illness, this response may be influenced by the social desirability to respond in such a manner, and actual participation in the PA programs may be less than projected. For this reason, and in order to guarantee regular PA practice, it would be advisable to account for factors like employees' time availability, family and work barriers, and motivation when planning workplace PA programs.

This study's key limitations are that its population comes from only one setting, therefore healthcare costs here estimated could be only representative for university employees, not allowing generalization to the general Mexican workforce. In particular, university employees' preferences may not represent those of employees in other workplace settings, because university workforce contains a relatively high proportion of individuals with advanced education. Furthermore, formal healthcare costs here considered, represent one part of the total cost of type 2 diabetes and hypertension. For example, research conducted in Latin America has shown that the indirect healthcare costs related to diabetes are higher than the direct ones, ${ }^{20}$ and the healthcare costs of diabetes and hypertension patients with medical complications are also higher than those without. $^{24}$

Some strenghts of this study include that this paper tackles an important issue: the need to provide evidence for the potential of workplace programs to reduce public burden attributable to preventable diseases; its focus on the medical costs of diabetes and hypertension in light of the intensity of in-and outpatient service use 
reported by a longitudinal national study; ${ }^{8}$ use of the PAR of diabetes and hypertension from a very similar worker population (urban Mexican worker population) for computing health care cost reduction:; ${ }^{14}$ and use of updated unit costs for healthcare services. ${ }^{12}$

In summary, we found that type 2 diabetes and HBP-related costs in the Mexican healthcare system could be reduced by involving university workers in workplace PA programs at recommended levels. This research meets the call to use analytical methods to reappraise healthcare priorities, and devise strategies for optimal resource allocation, utilization and organization of financial resources in the health care sector. The costs reduction from PA might directly impact resource allocation within the healthcare system, freeing money for use in diseases prevention and health promotion programs. ${ }^{8}$

\section{Acknowledgments}

This work was supported by the "Unidad de Investigación Epidemiológica y en Servicios de Salud", IMSS, delegación Morelos, México, the Universidad Autónoma de Tlaxcala and the "Équipe MA2D, Université Claude Bernard, Lyon 1". We acknowledge Emily Wentzell, Françoise Oudoire, Marie Christine, Lupita Moctezuma and all who participated in this project and thank them for their time and commitment.

Declaration of conflict of interests: The authors declare that they have no conflict of interests.

\section{References}

I. World Health Organization. Promoting physical activity for health - a framework for action in the WHO European region. Steps toward a more physically active Europe. Regional office for Europe, 2006 [consulted 2008 November 15]. Available at: http://www.euro.who.int/Document/NUT/ Instanbul_conf_edocl0.pdf.

2. Lara A, Yancey MK, Tapia-Conyer R, Flores Y, Kuri-Morales P, Mistry R, et al. Pausa para tu salud: reduction of weight and waistlines by integrating exercise breaks into workplace organizational routine. Prev Chronic Dis 2008;5:1-9.

3. Aguilar-Salinas CA, Olaiz G, Valles V, Ríos-Torres JM, Gómez-Pérez FJ, Rull JA, et al. High prevalence of low HDL colesterol concentrations and mixed hyperlipidemia in a Mexican nationwide survey. J Lipid Res 2001;42(8):1298-1307.

4. Olaiz-Fernández G, Rivera-Domarco J, Shamah-Levy T, Rojas R, Villalpando-Hernández S, Hernández-Ávila M, et al. Encuesta Nacional de Salud y Nutrición 2006. Cuernavaca México: Instituto Nacional de Salud Pública, 2006:19-23.

5. Instituto Nacional de Estadística, Geografía e Informática. Causas seleccionadas de mortalidad por sexo 2005. México:Estadísticas vitales, 2005:93. [consulted 2009 July 22]. Available at: http://www.inegi.org. $\mathrm{mx} /$ prod_serv/contenidos/espanol/bvinegi/productos/integracion/
sociodemografico/mujeresyhombres/2007/MyH_2007_3.pdf. 6. Gaede P, Vedel P, Larsen N, Jensen GV, Parving HH, Pederson O. Multifactorial intervention and cardiovascular disease in patients with type 2 diabetes. New Engl J Med 2003;348(5):383-93.

7. Hymel PA. Shifting the focus from cost to value: an employer perspective. J Manag Care Pharm 2006; I2(6 Suppl B):S6- 10; quiz S24-6.

8. Arredondo A, Zuñiga A, Parada I. Health care costs and financial consequences of epidemiological changes in chronic diseases in Latin America: evidence from Mexico. Public Health 2005; I 19:7 I I-720. 9. Calderón-Hinojosa F. México 2030, proyecto de gran visión. Eje 3. lgualdad de oportunidades. Cultura física y deporte. Resultados de los talleres temáticos. México D.F: Presidencia de la República Mexicana, 2008. [consulted 2008 September 2]. Available in: http://www.vision2030.gob. $\mathrm{mx} / \mathrm{pdf} / /$ 5analisis/ECYGDE_CYT.pdf.

10. McEachan RR, Lawton RJ, Jackson C, Conner M, Lunt J. Evidence, Theory and Context. Using intervention mapping to develop a worksite physical activity intervention. BMC Public Health 2008;8:326.

II. Proper KI, van Mechelen W. Effectiveness and economic impact of worksite interventions to promote physical activity and healthy diet. Technical paper prepared for the WHO/World Economic Forum joint event on preventing non communicable diseases in the workplace. Geneva:World Health Organization, 2007: I-63. [consulted 2009 january 22]. Available in: http://www.who.int/dietphysicalactivity/Proper_K.pdf. 12. Diario Oficial de la Federación. Costos unitarios de atención médica. México:Instituto Mexicano del Seguro Social, 2008:76-77.

13. Zhao W, Zhai Y, Hun J, Wang J, Yang Z, Kong L, et al. Economic burden of obesity-related chronic diseases in Mainland China. Obes Rev 2008;9(Suppl I):62-67.

14. Méndez-Hernández P, Flores Y, Siani C, Lamure M, Dosamantes-Carrasco LD, Halley-Castillo E, et al. Physical activity and risk of Metabolic Syndrome in an urban Mexican cohort. BMC Public Health 2009;9(276): I-I0.

15. Gill JM, Cooper AR. Physical activity and prevention of type 2 diabetes mellitus. Sports Med 2008;38(I0):807-824.

16. Tharkar S, Satyavani K, Viswanathan V. Cost of medical care among type 2 diabetic patients with a co-morbid condition-Hypertension in India.

Diabetes Res Clin Pract 2009;83(2):263-267.

17. Weyker D, Nichols GA, O'keeffe-Rossetti M, Edelsberg J, Khan ZM, et al. Risk-factor clustering and cardiovascular disease risk in hypertensive patients. Am J Hypertens 2007;20(6):599-607.

18. Consejo de Salubridad General/Instituto Nacional de Salud Pública. Guía para la conducción de estudios de evaluación económica para la actualización del Cuadro Básico de Insumos del Sector Salud en México, 2008:27-8. [consulted 2009 March 22]. Available in: http://www.csg.salud.gob. $\mathrm{mx} /$ descargas/pdfs/cuadro_basico/GUxA_EVAL_ECON25082008_2_ech.pdf. 19. Arredondo A, Zúñiga A. Economic consequences of epidemiological changes in diabetes in middle-income countries. The Mexican case. Diabetes Care 2004:27:104-09.

20. Lumbreras-Delgado I, Moctezuma-Ayala MG, Dosamantes-Carrasco LD, Medina-Hernández MA, Cervantes-Rodríguez M, López-Loyo MRR, et al. Estilo de vida y riesgos para la salud en estudiantes universitarios: hallazgos para la prevención. Rev Digital Universitaria 2009;10(2):1-12. 21 . Arredondo A, de Icaza E. Financial requirements for diabetes in Latin America: evidence and implications to the health system and to patients in Mexico. Diabetologia 2009;52(8):1693-1695.

22. Aldana SG, Greenlaw RL, Diehl HA, Salberg A, Merrill RM, Ohmine S. The effects of a worksite chronic disease prevention program. J Occup Environ Med 2005;47:558-564.

23. Chapman L. Meta-evaluation of worksite health promotion economic return studies. Am J Health Promot 2005;6: I- 16.

24. Villarreal-Ríos E, Mathew-Quiroz A, Garza-Elizondo ME, Núñez-Rocha G, Salinas-Martínez AM, Gallegos-Handal M. Costo de la atención de la hipertensión arterial y su impacto en el presupuesto destinado a la salud en México. Salud Publica Mex 2002;44:7-13. 
Appendix

\section{MATERIAL COSTS FOR A PHYSICAL ACTIVITY PROGRAM AT THE WORKPLACE}

Activity description and materials

Unit

Unite cost Unite cost Unite cost Subtotal Subtotal Subtotal (mean price) (down in price) (high price) (mean) (down) (high)

I. Information from:

\begin{tabular}{rrrrrr}
2.5 & 2.2 & 8.9 & 1530.0 & 1320.0 & 5340.0 \\
\hline 232.4 & 150.0 & 360.0 & 2324.0 & 1500.0 & 3600.0 \\
\hline 5.3 & 3.9 & 7.5 & 477.0 & 351.0 & 675.0
\end{tabular}

2. Sports

Swimming

\begin{tabular}{|c|c|c|c|c|c|c|c|}
\hline Weightlifting & paires (8) & 80.2 & 65.3 & 105.9 & 641.6 & 522.4 & 547.2 \\
\hline Ball & Unit(4) & 233.4 & 185.0 & 310.9 & 933.6 & 740.0 & 1243.6 \\
\hline Tech spring & Unit (8) & 59.9 & 52.1 & 92.1 & 479.2 & 416.8 & 736.8 \\
\hline Jump rope & Unit (8) & 22.8 & 20.5 & 46.3 & 182,4 & 164.0 & 370.4 \\
\hline Step & Unit (8) & 60.1 & 52.8 & 105.7 & 480.8 & 422.4 & 845.6 \\
\hline Trampoline & Unit (8) & 72.4 & 65.5 & 132.3 & 579.2 & 524.0 & 1058.4 \\
\hline Mat & Unit (8) & 45.3 & 42.3 & 60.5 & 362.4 & 338.4 & 484.0 \\
\hline \multicolumn{8}{|l|}{ Folkloric Ballet } \\
\hline Fancy-dress & Unit (8) & 236.4 & 210.0 & 288.2 & 1891.2 & 1680.0 & 2305.6 \\
\hline \multicolumn{8}{|l|}{ Yoga, Tai-chi } \\
\hline Mat & Unit (8) & 45.3 & 42.3 & 69.3 & 362.4 & 338.4 & 554.4 \\
\hline \multicolumn{8}{|l|}{ Football } \\
\hline Football & Unit (8) & 86.7 & 70.4 & 130.8 & 693.6 & 563.2 & 1046.4 \\
\hline Cone & Unit (25) & 15.3 & 13.5 & 19.8 & 382.5 & 337.5 & 495.0 \\
\hline Shirt & Unit (50) & 32.2 & 25.0 & 45.9 & 1610.0 & 1250.0 & 2295.0 \\
\hline Filets & pair (2) & 546.5 & 526.3 & 850.1 & 1093.0 & 1052.6 & 1700.2 \\
\hline \multicolumn{8}{|l|}{ Basketball } \\
\hline Basketbal & Unit (8) & 67.8 & 60.0 & 110.8 & 542.4 & 480.0 & 886.4 \\
\hline Maillots & Unit (25) & 32.2 & 25.0 & 459.0 & 805.0 & 625.0 & 1147.5 \\
\hline \multicolumn{8}{|l|}{ Volleyball } \\
\hline Volleyball & Unit (8) & 53.4 & 50.4 & 65.6 & 427.2 & 403.2 & 524.8 \\
\hline Fillet & Unit (2) & 421.8 & 365.0 & 702.5 & 843.6 & 730.0 & 1405.0 \\
\hline Additional instructors & Instructor (3) & 50000.0 & 36000.0 & 2000.0 & 80000.0 & 08000.0 & 216000.0 \\
\hline
\end{tabular}

3. Technology for assessing the impact of PA

\begin{tabular}{|c|c|c|c|c|c|c|c|}
\hline Computer & Unit (2) & 13625.0 & 4956,3 & 16523,2 & 27250.0 & 9912.6 & 33046.4 \\
\hline Laser printer & Unit (I) & 2164.1 & 856,4 & 6958,6 & 2164.1 & 856.4 & 6958.6 \\
\hline People counter & Unit (I) & 18645.0 & 14368,2 & 21054,9 & 18645.0 & 14368.2 & 21054.9 \\
\hline Spotlight & Unit (2) & 15565.0 & 7236,3 & 18157,7 & 31130.0 & 14472.6 & 36315.4 \\
\hline Electronic weight & Unit (3) & 3214.0 & 1526 & 3958,1 & 9642.0 & 4578.0 & 11874.3 \\
\hline Electrocardiogram & Unit (I) & 30624.0 & $24 \mid 24,3$ & 38477,4 & 30624.0 & $24 \mid 24.3$ & 38477.4 \\
\hline Spirometer & Unit (I) & 22647.0 & 19668 & 35699,3 & 22647.0 & 19668.0 & 35699.3 \\
\hline Check-up: glucose, triglycerides, LHD, cholesterol. & All & 1025.3 & 866,3 & 1363,5 & 1025.3 & 866.3 & 1363.5 \\
\hline
\end{tabular}

4. Prizes for winners

Trophy: For every winning team : 3 categories -males and females-

\begin{tabular}{lllllll} 
By discipline and sex (6) & 258.9 & 210,1 & 599,3 & 1553,4 & 1260.6 & 3595.8 \\
\hline
\end{tabular}

Prize : For every winning team (athletic clothes) By discipline and sex (6)

Trophy by categories. Swimming -males and femalesBy sex (6)

458.3

$\begin{array}{lllll}410,8 & 655,4 & 2749,8 & 2464.8 & 3932.4\end{array}$

Prize: Athletic clothes for each category of swimming

-males and females-

By sex (6)

$258.9 \quad 210$,

399,3

$\begin{array}{lll}1553,4 & 1260.6 \quad 2395.8\end{array}$

Prize for Yoga, Tai-chi, and dance (sportive clothes)

By sex (2)

365.3

210,1

399,3

244,2

$529,7 \quad 2191,8$

$1465.2 \quad 3178.2$

Total (Mexican pesos)

$350816.9 \quad 219522.7 \quad 444,725.1$

Total (US dollars)

$25852.4 \quad 16177.0 \quad 32772.6$

All costs were estimated by considering the lower, intermediate and upper prices

Costs were estimated in Mexican pesos and the subtotal costs were estimated in US dollars. Exchange rate, July 10, 2009, I dollar $=\mid 3.57$ pesos 